\title{
VIOLACIÓN Y TRANSGRESIÓN. MEDICINA FORENSE Y MORAL SEXUAL EN LA ESPAÑA DEL SIGLO XIX
}

\section{Amalio Lorente Carpena}

Universidad de Cádiz

\section{RESUMEN}

En este trabajo se examina la contribución del discurso médico-forense español del siglo XIX, a través de su aplicación en los casos de agresión sexual, a la legitimación del orden moral sexual de la época. Con este objetivo se analizan los principales tratados de Medicina Forense editados en nuestro país durante ese siglo.

PALABRAS CLAVE: Medicina Forense. Moral sexual. Violencia sexual. España. Siglo XIX.

RAPE AND TRASNGRESSION. FORENSIC MEDICINE AND SEXUAL MORALITY IN SPAIN IN THE 19TH CENTURY

\section{ABSTRACT}

The purpose of this paper is to analyse the importance of the contribution of the Spanish forensic medical discourse in the 19th century, and its application in cases of sexual harassment, to legitimize the sexual moral value of the time. For that reason we will analyse the main forensic medicine treaties edited in Spain during this century.

KEY WORDS: Forensic medicine. Sexual moral. Sexual harassment. Spain. $19^{\text {th }}$ century.

\section{INTRODUCCIÓN}

Este artículo trata sobre una forma específica de violencia, la sexual. Y dentro de este campo es nuestro propósito tratar de probar cómo el discurso médico-forense del siglo XIX, cuando se ocupa de esta cuestión, contribuye a la legitimación del orden moral sexual de la época.

El modo en el que aquí entendemos la moral sexual, como un conjunto de creencias y valores más o menos asumidos e interiorizados por los agentes morales, es el resultado de un entramado de discursos, así como de prácticas, 
que van configurando un modo particular de concebir la sexualidad. En este sentido, el discurso médico-forense, cuando se ocupa del cuerpo como objeto de violencia sexual, va a aportar una perspectiva interesante al respecto, y ello por dos razones, que serán las que articularán la argumentación de este trabajo.

En primer lugar, la visión médica, a diferencia de la filosófica o la teológica, aporta un punto de vista sobre la sexualidad que se presenta con pretensiones de cientificidad. No obstante, y es la opinión que mantenemos aquí, este discurso durante el periodo del que nos ocupamos, desde sus inicios modernos a finales del siglo XVIII hasta finales del siglo siguiente, va a ofrecer una legitimación de las creencias más o menos populares acerca del cuerpo y la violencia sexual, a través de afirmaciones que van a avalar los prejuicios que predominan en la época, referentes sobre todo al papel asignado a la mujer en el orden moral sexual.

En segundo lugar, la Medicina Legal, cuando se aplica a lo que durante el siglo XIX se conocen como «delitos contra la honestidad», no se limita a su función explícita de aportar luz a la dilucidación del delito, sino que, yendo más allá, se orientará a detectar, en una labor de contribución al orden moral imperante, las transgresiones que en el campo de la sexualidad son objeto de atención en este siglo. Especialmente se ocupará de aquellas que trastocaban el cuadro de las alianzas. La violación es la concreción en su máximo grado de la violencia sexual y es, por tanto, perseguida legalmente, pero el discurso médico se va a dirigir, no tanto a despejar dudas sobre la imputación al agresor, como a desenmascarar el posible fraude, la hipotética anuencia de la mujer, el falso estupro y, sobre todo y como tema central que atraviesa todo el discurso médico-legal decimonónico, a la verificación de la virginidad, como signo necesario para la creación del orden familiar legítimo. En este sentido, podemos afirmar que el informe forense se va a orientar, en gran medida, a la identificación de los signos que revelan la transgresión, como un dispositivo más de control de la mujer ${ }^{1}$.

De este modo, el tema de este artículo entronca, por una parte, con los trabajos que en las últimas décadas se han ocupado de la cuestión de la medicalización de la sexualidad ${ }^{2}$. Especialmente reseñable es la obra de Vázquez

1 Sobre el papel del informe forense como dispositivo de control de ciertos sectores de la población, mujeres, niños y sodomitas, cfr. FoUCAULT, M. (2001), Los anormales, Madrid, Editorial Akal, pp. 17-18.

2 La obra de referencia para el estudio de la medicalización de la sexualidad es FouCAUlt, M. (1995), Historia de la sexualidad. La voluntad de saber, Madrid, Siglo XXI. También cfr. Foucault, M. (1990), Historia de la medicalización. En FoucAult, M., La vida de 
García y Moreno Mengíbar, que aborda esta cuestión circunscribiéndola al ámbito español ${ }^{3}$. Y por otra parte, el tema que nos ocupa se relaciona con los innumerables estudios publicados en nuestro país que versan sobre las relaciones entre la Justicia y la Medicina.

los hombres infames, Madrid, La Piqueta, pp. 121-152 y FoucAult (2001). Si nos centramos en la historiografía que, desde una perspectiva de género, ha tenido como objeto la medicalización del cuerpo de la mujer, nos encontramos con dos líneas de investigación fundamentales, que además se encuentran estrechamente ligadas. Se trata de la función que históricamente ha desempeñado la Medicina en la construcción de las diferencias sexuales, y su papel en la justificación de la estratificación sexual de la sociedad. Al respecto cfr., entre otros, los trabajos de LAQueur, T. (1994), La construcción del sexo. Cuerpo y género desde los griegos hasta Freud, Madrid, Cátedra; SHIEBINGEN, L. (2004), ¿Tiene sexo la mente?, Madrid, Cátedra; Berriot SAlVADORE, E. (2003), El discurso de la medicina y la ciencia. En DubY, G. y PerRot, M., Historia de las mujeres. Del Renacimiento a la Edad Moderna, Madrid, Taurus, pp. 385431; Thomasset, C. (2003), La naturaleza de la mujer. En DuBY, G. y Perrot, M., Historia de las mujeres. La Edad Media, Madrid, Taurus, pp.72-104. Dentro de la producción historiográfica española referente a este tema, cfr. ORTIZ GóMEZ, T. (2006), Medicina, historia y género. 130 años de investigación feminista, Oviedo, KRK; ORTIZ GóMEZ, T. (2002), El papel del género en la construcción histórica del conocimiento científico sobre la mujer. En RAMOS, E. (ed.), La salud de las mujeres: hacia la igualdad de género en salud, Madrid, Ministerio de Trabajo y Asuntos Sociales, Instituto de la Mujer, pp. 29-42; JimÉnEz LuCEnA, I., CASTEllanOs, J. y RuIZ

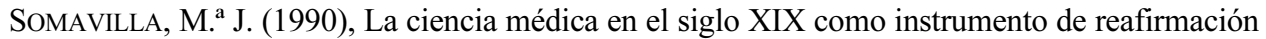
ideológica: La defensa de la desigualdad de la mujer a través de la patología femenina. En BAllarín, P. y Ortiz, T. (eds.), La mujer en Andalucía. Primer encuentro interdisciplinar de estudios de la mujer, Universidad de Granada, t. II, pp. 879-888; SIMÓN PALMER, M. ${ }^{a}$ C. (1984), La higiene y la medicina de la mujer española a través de los libros (ss. XVI- XIX). En DURÁN, M. ${ }^{\mathrm{a}}$ A. (ed.), La mujer en la historia de España. Siglos XVI-XX, Servicio de Publicaciones de la Universidad Autónoma de Madrid, pp. 71-84.

3 VÁzquez García, F. y Moreno Mengíbar, A. (1997), Sexo y Razón. Una genealogía de la moral sexual en España (siglos XVI-XX), Madrid, Editorial Akal. En esta obra se aborda la configuración de la sexualidad infantil a partir de las técnicas que medicalizan el problema del onanismo, la cuestión de la identidad sexual a partir de la inclusión dentro del campo médico del hermafrodita, sodomitas y todo el conjunto de perversos, y, por último, la formación de la feminidad a partir de figuras estigmatizadas como la prostituta, la ninfómana y la mujer histérica. Para una visión general acerca de los aspectos metodológicos, problemas teóricos, tipos de fuentes, enfoques, etc., que la historia de la sexualidad plantea en el contexto español, así como una amplia bibliografía al respecto, cfr. VÁZQUEZ GARCíA, F. (1996), Historia de la sexualidad en España: problemas metodológicos y estado de la cuestión, Hispania, 56 (3), n. ${ }^{\circ}$ 194, pp. 1007-1035. Respecto a la sexualidad en la España contemporánea cfr. sendos monográficos consagrados a esta cuestión en las revistas Asclepio e Hispania: La sexualidad y sus límites, Asclepio (1990), 42 (2); La sexualidad en la España contemporánea (1800-1950), Hispania (2004), 64, n. ${ }^{\circ} 218$. 
El interés que el discurso médico suscita en el siglo XIX es debido no sólo a que la Medicina se instituye en este siglo como un saber científico y objetivo, y por lo tanto imbuido de una considerable credibilidad, sino también a que la profesión médica experimenta a lo largo de esta centuria una relevancia política muy considerable, lo que acrecienta su influencia social.

En cierto sentido, podríamos decir que el Estado liberal moderno se configura en parte con la asunción de las funciones de la Higiene Pública en pugna con otras instancias como la familia o la caridad privada, para penetrar en un dominio que hasta ahora le era extraño: el cuerpo. El desarrollo y expansión de la actividad de la Higiene Pública va a ser especialmente relevante para entender el papel que la Medicina va a desempeñar en nuestra sociedad a partir de entonces, en tanto que será la encargada de diseñar la intervención dirigida por el Estado en el tejido social.

Los médicos, además, van a desempeñar una labor relevante en el ámbito político, tanto por su adhesión al movimiento liberal y su participación activa ocupando diversos cargos administrativos, como por sus pretensiones de influir en la producción legislativa ${ }^{4}$.

Por otra parte, es destacable el hecho de que durante el siglo XIX tiene lugar la consolidación de la Medicina Legal en el asesoramiento de procesos criminales, en el sentido de que la culpabilidad o inocencia del encausado depende en gran medida de los informes periciales que se elaboran al efecto. Esto va a llevar, no sólo a que los médicos enfrenten su conocimiento al dictamen judicial, sino que incluso consideren puesta en cuestión su credibilidad como saber, cuando las sentencias no se dictan en consonancia con lo expuesto por el forense. Las intervenciones médicas en el campo judicial de más resonancia serán aquellas que se orienten hacia la demostración de la exención de responsabilidad penal del encausado por demencia. Casos tan célebres como el de Juan Díaz de Garayo, el «Sacamantecas», serán percibidos por la profesión médica de la época como ocasiones privilegiadas donde se materialice la influencia de la Medicina en el campo del Derecho5.

4 Así autores como Ramón López Mateos (1771-1814) y Francisco Fabra Soldevilla (1778-1839), médicos de profesión, defenderán que el conocimiento que la Medicina suministra acerca del hombre debería servir de fundamento para la elaboración de las leyes de un Estado, cfr. MARTINEZ, J. (1990), Sexualidad y orden social: la visión médica en la España del primer tercio del siglo XIX, Asclepio, 42 (2), pp. 119-135. Unos años después, Pedro Mata presentará una argumentación similar, cfr. MATA, P. (1844), Importancia de la Medicina Legal y necesidad de su estudio, Madrid, Establecimiento Artístico-Literario de Manini y Compañía.

5 Respecto a los inicios de las relaciones entre la Medicina Legal en su vertiente psiquiátrica y el Derecho, cfr. Álvarez Peláez, R. y Huertas Gacía-Alejo, R. (1987), ¿Crimina- 
El tema de este trabajo se encuadra también dentro de la historia de la violencia sexual en España, tema que ha sido poco tratado por la historiografía de nuestro país, circunscribiéndose los estudios que existen a los periodos de la Edad Media y Moderna y a ciertas áreas geográficas ${ }^{6}$. No se encuentra publicado, sin embargo, en nuestro país ningún estudio sistemático sobre la historia de la violación correspondiente a la Edad Contemporánea, aunque es posible hallar algunas referencias históricas a esta cuestión en obras consagradas a la historia de la mujer o de la criminalidad. Fuera de nuestras fronteras la obra de referencia sobre este tema es la Historia de la violación de Georges Vigarello7, que abarca un periodo que va del siglo XVI al XX, y que se centra en Francia. Menos estudiado incluso es el asunto específico de nuestra investigación, la relación de la Medicina Forense española del siglo XIX con los delitos sexuales. Respecto a esta cuestión sólo encontramos un breve apartado que, dentro

les o locos?, Madrid, CSIC, pp. 25-56; Álvarez-URíA, F. (1983), Miserables y locos. Medicina mental y orden social en la España del siglo XIX, Barcelona, Tusquets, pp. 181-243; CAMPOS MARÍn, R. et al. (2000), Los ilegales de la naturaleza. Medicina y degeneracionismo en la España de la Restauración (1876-1923), Madrid, CSIC, pp. 53-103; GALERA, A. (1991), Ciencia y delincuencia, Sevilla, CSIC, pp. 9-103; MARTínEZ PÉREZ, J. (1992), Locura y criminalidad, Historia 16, 192 (abril), pp. 70-78; PESET, J.L. y PESET, M. (1975), Lombroso y la escuela positivista italiana, Madrid, CSIC, 1975, pp. 79-100. Sobre la historia de la Medicina Legal en general en España, cfr. Corbella, J. (1995), Antecedentes históricos de la Medicina Legal en Espa$\tilde{n} a$, Barcelona, PPU. Para lo referente a la formación del Cuerpo de Médicos Forenses en España y las diferentes legislaciones que regulaban sus funciones desde mediados del siglo XIX, cfr. PÉrez de Petinto, M. (1999), Comienzo y actualidad (en 1951) de la trayectoria corporativa Médico- forense, Revista Española de Medicina Legal, 23, n. ${ }^{\circ} 86-87$, pp. 5-44.

6 Cfr. Córdoba de La Llave, R. (1994), El instinto diabólico. Agresiones sexuales en la Castilla medieval, Servicio de Publicaciones de la Universidad de Córdoba; CóRDOBA DE LA Llave, R. (1993), Violencia sexual en la Andalucía del siglo XV. En LóPEZ BeltrÁN, M. ${ }^{\mathrm{T} T}$. (ed.), Las mujeres en Andalucía. Actas del segundo encuentro interdisciplinar de estudios de la mujer en Andalucía, Málaga, Servicio de Publicaciones de la Diputación Provincial de Málaga, t. II, pp. 105-126; BAZÁN, I. (1995), Delincuencia y criminalidad en el País Vasco en la transición de la Edad Media a la Edad Moderna, Vitoria, Departamento de Interior del Gobierno Vasco; MANTECón Movellán, T. (2002), Mujeres forzadas y abusos deshonestos en la Castilla moderna, Manuscrits, 20, pp. 157-185. Sobre la historia de la regulación jurídica de la violación en España hasta el siglo XVIII, vid. RodríguEZ ORTIZ, V. (1997), Historia de la violación. Su regulación jurídica hasta fines de la Edad Media, Consejería de Educación y Cultura de la Comunidad de Madrid; Rodriguez OrTIZ, V. (2003), Mujeres forzadas. El delito de violación en el Derecho castellano (siglos XVI-XVIII), Almería, Universidad.

7 Vigarello, G. (1999), Historia de la violación. Siglos XVI-XX, Madrid, Cátedra. 
del contexto de la agresión en general a la mujer, le dedica el forense Lorente Acosta en su obra Agresión a la mujer: Maltrato violación y acoso ${ }^{8}$.

Para abordar el problema que nos hemos propuesto en este trabajo tomaremos como objeto de estudio la producción tratadística de Medicina Legal española entre finales del siglo XVIII y finales del XIX, tanto obras originales editadas en nuestro país, como traducciones de obras extranjeras. Hacemos la excepción con el tratado de Devergie, una obra que se puede clasificar como clásica, muy citada en los otros tratados y de la que no conocemos una traducción al español.

Si bien la relación de obras utilizadas no es exhaustiva, sí que puede ser considerada muy representativa, en tanto que figuran las de los autores más importantes de la época (Foderé, Orfila, Devergie, Mata, Tardieu, Casper, Hoffman...) que sirvieron de referencia para el resto de tratados editados en nuestro país. Entre todos, consideramos como el más significativo entre los escritos originalmente en español, el de Pedro Mata. Su tratado, con varias ediciones (1844, 1856, 1857, 1866, 1874 y póstumamente en 1903), es sin duda el de mayor envergadura y calidad de los que se editaron en España en la época, especialmente a partir de la tercera edición. Fue además designado como libro de texto. El propio Mata es asimismo un personaje relevante en su época: es el responsable de la creación de la primera cátedra de Medicina Legal en España, contribuyó a la formación del Cuerpo de Médicos Forenses, influyó en la creación del Registro Civil, a parte de ocupar diferentes cargos políticos como gobernador civil de Madrid, alcalde de Barcelona, diputado a Cortes, etc. Por todo ello, tanto su obra como su personalidad pueden ser consideradas como las más influyentes dentro del campo de la Medicina Legal de la segunda mitad del siglo XIX en España ${ }^{9}$.

\section{EL DEBATE EN TORNO A LA VIRGINIDAD}

El cambio que supuso el paso del Antiguo Régimen, con una imagen de la mujer dependiente de un orden jurídico fuertemente androcéntrico, al Estado liberal, en el que se da cierto reconocimiento de la individualidad femenina al margen del ámbito conyugal, queda reflejado en la tratadística médicoforense del siglo XIX. Cambio que se produce parejo al que tiene lugar con la

8 Lorente Acosta, M. y LoRente Acosta, J.A. (1999), Agresión a la mujer: maltrato, violación y acoso, Granada, Comares, pp. 32-37.

9 Sobre la relevancia de la obra de Mata, cfr. CoRBella (1995), pp. 275-283. 
sustitución de las antiguas legislaciones (Las Partidas y Novísima Recopilación) por los Códigos Penales de 1848 y 1870.

El cuerpo de la mujer, en las legislaciones decimonónicas, no será ya considerado explícitamente merecedor de protección jurídica en tanto que depositario del honor patriarcal, tal como se entendía en los textos legales del Antiguo Régimen ${ }^{10}$. No obstante, y como vestigio de la época precedente, la virginidad como signo de la honestidad de la mujer, continuará durante todo el siglo XIX siendo contemplada como un valor moral de primer orden ${ }^{11}$. De ahí que gran parte del interés del discurso médico forense se centre en la identificación de los signos de la virginidad, y más en concreto del que se considera como más relevante, el himen.

Si atendemos a los tratados de Medicina Forense que se publican en nuestro país a finales del siglo XVIII y en parte del XIX, podemos observar que el tema de la violencia sexual se encuentra en dependencia de otro al que se le atribuye una mayor importancia: la honestidad de la mujer, cuya manifestación física, como ya hemos dicho, creen encontrarla en la virginidad. En este sentido, aunque el interés forense se centre en dos modalidades de delito, el estupro y la violación, será el primero el que más atención acapare. Hasta la promulgación del Código Penal de 1848, por estupro no sólo se entiende la pérdida de la virginidad fuera de la esfera conyugal, ya sea por la concurrencia de falsas promesas de matrimonio o seducción, sino que se habla también de un estupro violento que equivaldría a la fuerza o violación. A partir de 1848 ya se diferencia al estupro de la violación tanto en la ley como en la

10 En Las Partidas, se detallan cuáles eran los motivos por los que la violación se consideraba un hecho grave. Básicamente estos estaban referidos a la honestidad de la mujer, por un lado, y por otro, a la honra de los varones emparentados con ella. Vid. Las siete Partidas del Sabio Rey don Alonso el nono, nueuamente Glosadas por el Licenciado Gregorio Lopez del Consejo Real de Indias de su Magestad, (1555), Salamanca, ed. facsímil, Boletín Oficial del Estado, Madrid, 1985, partida 7, título XX. Sobre los bienes jurídicos protegidos por el Derecho en el delito de violación hasta el siglo XIX, cfr. RODRIGUEZ ORTIZ (2003), pp. 76-79.

11 La vinculación en la mujer entre el honor y la honestidad, entendiendo por esta la pureza sexual, tendrá una pervivencia en el imaginario español hasta bien avanzado el siglo XX. En el hombre, por el contrario, es la masculinidad, la «hombría», lo que se encuentra en la base de la honorabilidad. Pero en el honor del hombre está implicada igualmente la pureza de su madre, esposa, hijas y hermanas, lo que conlleva el deber de defender esta virtud. Cfr. PitT-Rivers, J. (1979), Antropología del honor o política de los sexos, Barcelona, Editorial Crítica. En este sentido, se puede interpretar que la finalidad protectora que las leyes ejercen sobre la mujer en el campo de los delitos de índole sexual durante el siglo XIX y parte del siglo XX, especialmente en el caso de algunas figuras penales como el rapto o el estupro, se encuentra tácitamente en dependencia de la preservación del honor masculino. 
práctica forense, aunque en los tratados médicos se utilice en ocasiones el término «estupro» para referirse a la violación de una menor.

En las postrimerías del siglo XVIII encontramos varios tratados en los que el tema de la agresión sexual no requiere una atención independiente del de la virginidad $^{12}$, de hecho, generalmente se trata de la cuestión del estupro, que como ya hemos indicado no tiene por qué estar necesariamente ligado a la violencia, aunque sí a la virginidad. En el tratado que Domingo Vidal publica en 1783 dedica un breve capítulo al tema de la desfloración, ocupándose de aquellos signos que pueden delatar la pérdida reciente de la virginidad, sin tratar expresamente la cuestión de la violencia sexual ${ }^{13}$. Es cierto que indica ciertas señales como pruebas de una agresión sexual, tales como el entumecimiento, equimosis, dificultad para caminar, pero todas ellas caen dentro de la consideración general del capítulo sobre el desfloramiento.

Trece años después, Fernández del Valle, en la misma línea que Vidal, mantiene que el interés de la Medicina Forense debe orientarse hacia el descubrimiento del estupro, y como por este entiende la pérdida de la virginidad, considera que primero deben conocerse los signos que apunten a su presencia ${ }^{14}$.

De una forma más detallada encontramos esta idea expuesta en la obra de Plenk, el que también justificará la inclusión en su tratado de un apartado que se ocupe de los signos que indican ausencia de virginidad por las siguientes razones:

«1 Quando la casada acusa al marido de impotente, y pide el divorcio.

2 Quando el marido, ó por mejor decir el novio, juzga que la novia está corrupta antes de casarse, y por eso rehusa el casarse.

3 Quando en el foro se queja una doncella de que la han infamado su honor.

12 Hay que tener en cuenta que hasta 1848 la normativa que regulaba este tipo de delitos era la contenida en Las Partidas y la Novísima Recopilación. En el primer texto mencionado se diferencia entre «De los que yazen con mugeres de orde, o con biuda que biua honeftamente en su casa, o con virgenes por falago, o por engaño non les faziendo fuerça» y «De los que fuerçan, o lleuan robadas las virgenes, o las mugeres de orden, o las biudas que biuen honeftamente»; vid. Las siete Partidas..., partida 7, titulos XIX y XX. En ninguno de los dos supuestos se contempla el caso de la mujer soltera no virgen. Tampoco en la Novísima Recopilación se hace mención alguna a esta circunstancia, tratando solamente de las relaciones ilegítimas que puedan darse entre los que sirven en una casa y las parientas, barraganas o sirvientas del señor.

13 Vidal, D. (1783), Cirugía Forense ó arte de hacer las relaciones chirurgico-legales, Barcelona, ed. facsímil, 1987, Seminari Pere Mata, Departament de Medicina legal i toxicología de la Universitat de Barcelona, pp. 56-58.

14 Fernández del Valle, J. (1796), Cirugía Forense General y Particular, 3 vols., Madrid, Imprenta de Aznar, t. I, p. 307. 
4 Quando una doncella desflorada intenta en el foro que se la tenga por incorrupta» ${ }^{15}$.

Plenck se centra en aquellas cuestiones que son alusivas al orden matrimonial, y cuando se refiere, en el tercer punto, a que una doncella puede presentar demanda porque «la han infamado el honor», no tenemos por qué entender que esto haya tenido lugar necesariamente de forma violenta, puesto que el estupro, cuando tiene lugar por el concurso de la seducción, es igualmente considerado como delito. El hecho de que estas circunstancias sean las que acaparen la atención del discurso médico de la época, en consonancia, claro está, con lo recogido en los textos jurídicos coetáneos, nos lleva a pensar que todavía a finales del siglo XVIII no es tan importante la agresión sexual en sí misma como la cuestión del esclarecimiento de la honorabilidad de la ofendida. Esto hay que entenderlo en un contexto donde la pérdida de la virginidad de forma extraconyugal, y consecuentemente del honor, suponía la desaparición de un capital simbólico fundamental en el mercado matrimonial, donde las mujeres eran un bien de intercambio básico para sellar las alianzas $^{16}$. De modo que podemos afirmar que en este momento la tratadística forense contribuye a la permanencia de un determinado orden moral patriarcal, dentro del cual la sobrevaloración de la virginidad constituye un componente fundamental.

Con el inicio del siglo XIX se publica en España la traducción de la obra de Foderé Las leyes ilustradas por las ciencias físicas ó tratado de medicina legal e higiene pública, que va a suponer un cierto cambio de perspectiva con respecto al tratamiento de la violencia sexual. Foderé va a dedicar un capítulo al tema de la virginidad, y como ya hiciera Plenck, justifica el mismo por una serie de cuestiones que se suscitan en los tribunales sobre la presencia o ausencia de las señales de la virginidad:

«1. ${ }^{\circ}$ Una persona desflorada puede pretender que es todavia doncella para separarse de su marido, ó para permanecer en su compañía: $2 .^{\circ}$ una muger que no haya perdido la virginidad, puede decir, al contrario, que ha sido desflorada, ya para que

15 Plenk, J.J. (1796), Medicina y Cirugía Forense o Legal, Madrid, Imprenta de la viuda e hijos de Marín, pp. 102-103.

16 Para un análisis más detallado acerca del papel del honor femenino como capital simbólico en la sociedad patriarcal, cfr. BOURDIEU, P. (2005), La dominación masculina, Barcelona, Anagrama, pp. 59-67. 
la doten, y ya tambien para obligar á alguno á que se case con ella: $3 .^{\circ}$ semejantes qüestiones se verifican igualmente en las acusaciones de violación» ${ }^{17}$.

Nuevamente la atención forense se dirige hacia los signos de la virginidad, por las mismas razones aludidas anteriormente (básicamente que el honor de la mujer soltera está irremisiblemente unido al de la virginidad). Foderé añade que el interés hacia los signos de la presencia o ausencia de la virginidad son útiles, asimismo, para los casos de acusaciones de violación, pero yendo un poco más allá de los tratados precedentes, va a dedicar un capítulo a este asunto, incluyendo, de este modo, la presencia o ausencia de la virginidad como dato para esclarecer los casos de violación.

En la traducción del tratado de Belloc que hace Francisco de Burgos y Olmo y que se edita en 1819 encontramos una definición de virginidad que nos puede ilustrar acerca de cómo se entiende esta más allá de los límites de la objetividad científica:

«La virginidad es el estado particular de la hembra á quien aun no ha tocado el macho; es una flor preciosa, que bajo pena de infamia obligan á conservar hasta un legitimo matrimonio, el honor, la virtud y la religion en los paises en que reynan las buenas costumbres» ${ }^{18}$.

La virginidad es, pues, un estado cuyo valor simbólico trasciende el ámbito privado de la mujer. No es, pues, algo que se le atribuya a su intimidad, forma parte del dominio social, condición de un legítimo matrimonio, base del orden social y moral. Al valor atribuido a la virginidad hay que sumarle la creencia, muy arraigada durante todo el siglo XIX, de que son las menores y las jóvenes vírgenes las más susceptibles de sufrir un atentado sexual ${ }^{19}$.

17 Foderé, E. (1801), Las Leyes Ilustradas por las Ciencias Físicas ó Tratado de Medicina Legal y de Higiene Pública, 8 vols., Madrid, Imprenta de la Administración del Real Arbitrio de Beneficencia, t. II, pp. 10-11.

18 Belloc, J.J. (1819), Curso de Medicina Legal Teórica y Práctica, traducido al castellano con notas por Francisco de Burgos y Olmo, Madrid, Imprenta que fue de García, p. 35.

19 Vid. Peiró y Rodrigo, P. y Rodrigo y MartíneZ, J. (1832), Elementos de Medicina y Cirujía Legal, arreglados a la legislación española, Zaragoza, Oficina de D. Agustin Sevil, Regente Vicente Ventura, p. 97; Devergie, A. (1840), Médecine Légale Théorique et Pratique, 2 vols., París, Germer Baillière, Libraire-Éditeur, p. 370 bis; BRIERRE DE BOISMONT, A. (1841), Manual de Medicina Legal y Forense, traducido al castellano por B. Martínez, Barcelona, Imprenta de los Herederos de Roca, pp. 159-160; OrfILA, M. (1847), Tratado de Medicina Legal, 4 vols., traducido de la $4 .^{\text {a }}$ edición francesa y arreglado a la legislación española por Enrique Ataide, Madrid, Imprenta de Don José María Alonso, t. I, p. 148; HofmAnN, E. 
Por estas razones, la cuestión de la virginidad tendrá un interés crucial en el asesoramiento médico pericial en el siglo XIX, tanto en las causas seguidas por agresión sexual como por las de estupro. No obstante, el tema no estará exento de cierto debate que se irá produciendo a lo largo de esta centuria.

Podemos considerar las siguientes cuestiones como las más debatidas en este siglo: en primer lugar, se trata de determinar si la virginidad es física y/o moral. Si se admite, como hacen la mayoría de los médicos del siglo XIX, la existencia de la virginidad física, el segundo problema es el de la existencia y naturaleza del himen como signo de la integridad virginal, y por último, dado que la mera constatación de la presencia o ausencia del himen no será considerada como prueba definitiva de si ha habido cohabitación, se tomará en cuenta la concurrencia de otra serie de signos indicativos de la existencia o pérdida de la virginidad.

\section{Virginidad quoad corpus y virginidad quoad animam}

La cuestión acerca de qué puede entenderse por virginidad ha sido polémica en la tratadística médico-legal. En una tradición antigua se suele diferenciar entre una virginidad quoad animam, o virginidad moral, y otra quoad corpus, o física.

Cuando Zaccias, en su obra Quaestiones medico-legales, se ocupa del tema de la virginidad y el estupro, en el título segundo del libro cuarto, empieza la primera cuestión tratando acerca de qué se entiende por virginidad. Su primera afirmación se dirige a dejar claro que se está refiriendo a la virginidad material o corporal y no a la formal o mental. Una doble manera de entender la virginidad: una física, que como veremos se suele circunscribir a la integridad del himen como signo, y otra mental, referida a la pureza moral de la mujer. De modo que, según esta clasificación, el estado de la mujer puede reunir ambas condiciones o bien faltarle alguna de ellas, o las dos:

«Neque enim minus Virgo dici potest, quae virginalia claustra alio instrumento, quam virili disrupit, quam si pedem, aut manum disrupisset (...) licet si id lasciviens praestitisset, mentalem virginitatem illico absque dubio amisset» ${ }^{20}$.

(1882), Elementos de Medicina Legal y Toxicología, versión española a cargo de M. Carreras Sanchis, Madrid, Imprenta de Enrique Teodoro, p. 62.

20 Zaccias, P. (1771), Quaestiones medico-legales, Venecia, libro IV, p. 236. «Pues no puede llamarse menos virgen la que rompió las barreras virginales con otro instrumento distinto 
Por lo tanto, si bien la existencia del himen es garantía de la existencia de la virginidad física, su ausencia no debe interpretarse como signo inequívoco de que la mujer haya tenido comercio sexual con varón, ni siquiera de su falta de honestidad.

Esta distinción entre virginidad quoad animam y virginidad quoad corpus no sólo es importante desde el punto de vista de la moralidad de la mujer, sino que lo será más, en este contexto, por una cuestión técnica, en el sentido de que el médico forense no es competente para pronunciarse sobre la virginidad de la mujer o su ausencia, si no es sobre la base de un signo físico.

Pedro Mata afirma en el Vademecum de Medicina y Cirugía que «la palabra virgen nos da la idea de una muger que no ha tenido concúbito con varon. Si no relacionamos este estado con algun hecho material que sea consecuencia de este concúbito, la virginidad no podrá ser probada ${ }^{21}$. Efectivamente, el problema se plantea en el ámbito del peritaje forense: los médicos sólo pueden emitir un informe acerca de si ha habido estupro o no, en el caso de que puedan contar con una señal física o material de que este ha tenido lugar. Mata se opone así a la contemplación por parte del médico forense de la virginidad quoad animam, porque en el caso de que se tuviera en cuenta, obviamente, el dictamen médico quedaría sin el carácter objetivo requerido para ser digno de consideración en el tribunal de justicia, puesto que implica un desplazamiento hacia la voluntad de la mujer, hacia el uso propio o forzado de su cuerpo. Entraríamos en el terreno, del que nos ocupamos más adelante, de si ha habido consentimiento o no en el acto que se denuncia, lo que no es competencia del médico sino del juez. No sería, pues, el signo físico el que determinaría si ha tenido lugar la comisión del delito, sino la voluntad forzada o la incontinencia de la mujer. Los motivos de Mata para descartar que se contemple desde un punto de vista profesional esta clasificación son razonables si se tienen en cuenta cuáles son sus pretensiones. No es posible hacer de la Medicina Legal un saber objetivo si en las consideraciones sobre la violencia o la transgresión sexual entran variables tan oscuras al saber médico como la moral íntima de la mujer. Porque es esa la cuestión que se debate: la virginidad no puede ser un estado que dependa de la virtud o lascivia de la mujer, sino que debe ser un signo físico cuya existencia o ausencia pueda ser constatado en el reconocimiento médico (a pesar de lo cual, en los procesos crimi-

del viril que si se hubiera roto el pie o la mano (...) aunque si lo hubiera realizado con lascivia, sin duda habría perdido la virginidad mental».

21 Mata, P. (1844b), Vademecum de Medicina y Cirugía, 2 vols., Madrid, Imprenta de Manini y Cía., t. I, p. 49. 
nales por delitos contra la honestidad las cuestiones referentes a la conducta moral de la mujer serán tenidas muy en cuenta).

Mata vuelve sobre la cuestión en la 2. ${ }^{\text {a }}$ edición de su obra, titulada ahora Tratado de Medicina y Cirugía Legal. El debate lo centra en esta ocasión contra aquellas «autoridades que se han declarado abiertamente contra los procedimientos jurídicos sobre la averiguación de los delitos de incontinencia» ${ }^{22}$. En concreto va a arremeter contra Buffon, quien niega el carácter sensible de la virginidad. El naturalista francés afirma en una cita recogida por Mata que

«los hombres, celosos de las primicias de todo género, han dado siempre grande importancia á todo lo que ellos han creído haber gozado los primeros; esta especie de locura ha hecho un ser real de la virginidad de las mugeres. La virginidad, que no es sino un ser moral, una virtud que tan solo consiste en la pureza del corazon, se ha hecho un objeto físico por el cual se han preocupado los hombres; han establecido sobre él opiniones, usos, ceremonias, supersticiones y hasta juicios y castigos; se han autorizado los abusos mas ilícitos, las costumbres mas deshonestas; se han sometido al exámen de matronas ignorantes y espuestos á las miradas de médicos prevenidos las partes mas secretas de la naturaleza, sin pensar que semejante indecencia es un atentado contra la virginidad, que el intentar reconocerla es violarla, y que toda situacion vergonzosa, todo estado impúdico, del cual tenga que ruborizarse una joven interiormente, es una verdadera desfloracion». ${ }^{23}$

Llama la atención en esta cita la defensa a ultranza que Buffon hace del sentimiento íntimo de la mujer. Aunque obviamente moralizante, el discurso de Buffon está más próximo al reconocimiento de una intimidad personal, se trata de una virginidad moral, que identifica con la pureza, con la virtud, pero que a fin de cuentas no se reduce a una señal física, que por lo tanto pertenece a la mujer en tanto que voluntad y no como naturaleza. La integridad de la mujer se ve igualmente violentada por la agresión del violador como por el reconocimiento médico posterior, y no es este, según la definición de Buffon de la virginidad, el que pueda determinar si aquella está presente o no. Es decir, se trata más de un estado moral que escapa a la observación minuciosa del médico, que de un signo físico que pueda ser objeto de ciencia.

Para responder al punto de vista de Buffon, Mata va a presentar un recorrido etnológico sobre las diferentes consideraciones de la virginidad para

22 Mata, P. (1846), Tratado de Medicina y Cirugia Legal, 2 vols., Madrid, Imprenta de Suárez, t. I, p. 100.

23 MATA (1846), t. I, p. 101. 
concluir que «la virginidad no tiene un valor real absoluto, y que si es delito destruirla, no lo es sino donde se considere como una prenda apreciable» ${ }^{24}$. Y a pesar de esa afirmación relativista, cerrando filas en defensa de la función del médico forense, argumenta que independientemente de una supuesta virginidad moral, o quoad animam, existe la virginidad quoad corpus, es decir, la del cuerpo, la física, la anatómica, a favor de la que argumentará extensamente. No discutirá, pues, que exista una integridad moral de la mujer, una salvaguarda de su virtud, pero eso no puede ser objeto del saber médico, trasciende sus competencias.

En la tercera edición de este tratado, en 1857, corregida y reformada, Mata mantendrá una postura diferente respecto a esta cuestión. Nuevamente apoyándose en la cita de Buffon, vuelve a confirmar la existencia de la virginidad quoad corpus, pero ahora sus argumentos se orientan en sentido contrario a los mantenidos años atrás, es decir, considera ahora que el reconocimiento forense de la demandante por estupro raramente aporta luz en el proceso.

Las razones que han llevado a Mata a este cambio obedecen a un nuevo planteamiento metodológico que este autor ha adoptado a partir de la maduración de su propia perspectiva filosófica, que ya había plasmado en obras como Sinopsis filosófica de la química, Examen crítico de la homeopatía o Tratado de la Razón Humana en estado de salud y enfermedad, con aplicacion á la práctica del foro ${ }^{25}$. En concreto, si en las dos ediciones anteriores del Tratado de Medicina y Cirugía Legal se había limitado, según el confiesa, a dar forma a las ideas ajenas, en esta nueva edición sí encontramos una producción propia y original, que en sus planteamientos respecto al tema que nos ocupa se mantendrá inalterable hasta la última edición del tratado que se publica en vida del autor, esto es, la 5. ${ }^{\text {a }}$ edición en 1874.

Sobre el asunto que estamos tratando sostendrá, en primer lugar, la imposibilidad de determinar de modo inequívoco si ha tenido lugar la desfloración o no. Cita el caso que Parent Duchâtelet aporta respecto al examen que llevó a cabo de prostitutas de París y de cómo muchas de estas mostraban signos de apariencia de virginidad. En el mismo sentido cita a Toulmouche, quien en los Anales de higiene pública y de Medicina legal publicó un escrito sobre los delitos contra la honestidad, donde explicaba su experiencia durante veintiocho años en los tribunales, durante los cuales tuvo que informar sobre casos de estupro, y en gran parte de ellos no pudo encontrar alteraciones en los ge-

24 MATA (1846), t. I, p. 103.

25 Respecto a este cambio vid. MAtA, P. (1857), Tratado de Medicina y Cirugía Legal Teórica y Práctica, 2 vols., Madrid, Bailly-Bailliere, prólogo, pp.VII-XII. 
nitales de las demandantes. En concreto, de veintiséis observaciones de esta naturaleza que hizo, sólo había cinco o seis casos en los que hubo rotura del himen y algunos otros vestigios de los órganos genitales externos. En conclusión, según Mata, «ni la presencia de esos signos anatómicos es una prueba decisiva de que no ha habido el atentado, ni su ausencia lo es tampoco de una cópula estupradora» ${ }^{26}$. Esto le lleva a otra reflexión, que curiosamente se aproxima a la opinión de los que como Buffon hacen prevalecer el valor de la virginidad moral de la mujer frente a la física. Efectivamente, dado que no hay signos inequívocos acerca del estupro o el atentado, la situación jurídica en la que queda la mujer agredida resulta muy ambigua, ya que se puede dar la situación de que una mujer sea violada aun cuando no se haya destruido el himen. Y entonces añade: «Una jóven puede quedar completamente vírgen, anatómicamente hablando, y ser desflorada completamente en el sentido moral del delito» ${ }^{27}$. Aquí hemos de ver, pues, un reconocimiento explícito de la importancia de una virginidad quoad animam, reconocimiento que apunta hacia la valoración del daño moral que la violencia sexual produce en la mujer, independientemente de la destrucción del himen, con lo cual se entraría en conflicto, según él, con lo que está legislado ${ }^{28}$.

Por otra parte, por lo que su experiencia le ha aportado cuando ha sido llamado para testificar sobre casos de estupro, afirma no haber tenido el convencimiento de que el acto denunciado se hubiese producido o no, tan sólo por el análisis de los órganos sexuales. Más bien, se ha inclinado por la sospecha de que la causa motivo de la denuncia es producto de la superchería.

Dada esta incredulidad en la infalibilidad del reconocimiento forense para determinar la consumación del estupro, Mata va a admitir que sería ventajoso para la moral el abandonar estas prácticas por lo que conlleva de sufrimiento de una nueva vergüenza para la mujer, que se ve sometida a las miradas e

26 MATA (1857), t. I, p. 285.

27 Mata (1857), t. I, p. 286.

28 Con el Código Penal de 1848 se estableció una gradación de los delitos que implicasen una agresión sexual; esta normativa permaneció inalterable hasta la promulgación del Código Penal de 1928. Aunque no se especificara en la ley, en la práctica se tipificaban como abusos deshonestos desde los tocamientos a la penetración anal de niños. Para que se considerase el atentado como violación debía producirse el coito vaginal completo; en el caso de que este no se llevase a cabo, pero se apreciase la intención clara de realizarlo, se tipificaba como tentativa de violación. El reconocimiento pericial y su constatación de la permanencia o destrucción del himen, después de una agresión sexual, resultaban, pues, determinantes en la tipificación penal del hecho. 
incluso al tacto de hombres extraños en sus partes más íntimas ${ }^{29}$. Pero además del perjuicio moral que se podría evitar, añade que tampoco «perdería nada la administracion de justicia en abolir tambien en los casos de estupro las prácticas hasta aquí usadas, ó sea los reconocimientos facultativos $»^{30}$ y aunque reconoce que no se vaya a prescindir de los mismos, recomienda que los jueces lo soliciten sólo cuando los demás datos indiquen que dichos reconocimientos puedan aportar alguna luz al caso ${ }^{31}$.

\section{El signo específico de la virginidad}

Una vez establecida la existencia de la virginidad física, la siguiente cuestión es la de determinar cuál sea la naturaleza de su signo específico, esto es el himen. Es recurrente en los tratados de Medicina Legal el iniciar el capítulo referente a esta cuestión tratando sobre las diferentes opiniones acerca de la existencia o no de esta membrana. Hay quienes la afirman por haberla encontrado siempre (Haller, Heister, Riolan, Devergie, etc.) y quienes confiesan haberla hallado muy rara vez (Falopio, Versalio, Laurent, etc.). Pero siempre se le ha atribuido un valor simbólico de una gran trascendencia moral. En una cita recogida por Plenk de Haller se afirma que:

«No hallándose el himen sino en la especie humana, debemos creer que está destinado á algunos fines morales, y especialmente para conocer la virginidad, para que de este modo la casta doncella pueda defender su honor» ${ }^{32}$.

Así pues, la cuestión tiene una doble vertiente, por una parte se trata del único signo sobre el que se puede basar un diagnóstico más o menos objetivo

29 Vid. MATA (1857), t. I, pp. 283-284. Esta propuesta ya se encontraba en el Vademecum, pero no la sostiene con tanta contundencia, más bien dice que aunque la exploración suponga un nuevo atentado contra la mujer, como de hecho hay que hacerla, sugiere que se haga lo antes posible para que se pueda verificar la desfloración. Vid. MATA (1844b), t. I, p. 75.

30 MATA (1857), t. I, p. 287.

31 Yáñez también se va a pronunciar por el abandono de estas prácticas para las denuncias de estupro, afirmando que sólo para los casos en los que aquel haya sido reciente se puede reconocer la posibilidad de establecer una relación inmediata entre la fecha de su comisión y los datos que aporte el reconocimiento médico; para los demás, afirma, nada puede hacer el médico. Vid. YAÑEZ, T. (1884), Elementos de Medicina Legal y Toxicología, Madrid, Imprenta de Enrique Rubiños, p. 306.

32 PLENK (1796), p. 104. 
sobre una pretendida virginidad física en un análisis pericial, por otra parte, se trata de un elemento anatómico cuya significación moral no tiene parangón con ningún otro órgano o estructura corporal. De este modo se entiende por qué el debate acerca de su existencia es tan controvertido. Además, en los reconocimientos periciales nunca se puede tener la certeza de que su ausencia haya sido debida al estupro ya que, si siempre es posible encontrarlo en las niñas de corta edad, más difícil es verificar su presencia en una edad más avanzada porque «se destruie poco á poco á medida que van creciendo (las niñas) $»^{33}$ según recoge Vidal del testimonio de Heister.

Causas como la menstruación, la leucorrea, ulceraciones en la vagina, además de otras causas mecánicas, son entendidas ya en los últimos tratados del siglo XVIII y primeros del XIX como susceptibles de hacer desaparecer dicha membrana.

Respecto a su configuración, desde muy pronto se definen y clasifican las formas bajo las cuales se puede encontrar (anular, semianular, semilunar, filamentoso, con orificio central, etc.), pero además se le atribuye cierta capacidad de regeneración. Así Foderé cree que

«mientras se está creciendo, puede renovarse con mucha freqüencia esta prueba equívoca de la virginidad, con tal que haya una interrupción suficiente para dar tiempo á que se reunan las partes, y vuelvan a su primer estado» ${ }^{34}$.

Creencias de este tipo son desechadas prontamente, pero la discusión sí será muy frecuente respecto a las circunstancias bajo las cuales puede ser encontrado.

Devergie circunscribirá el debate de la cuestión a tres objeciones que generalmente se hacen a la constatación de la existencia del himen, dando por sentado que la virginidad es un estado físico. Las objeciones se refieren a que una mujer haya podido practicar el coito sin que el himen sea destruido, a que el himen pueda faltar y en su lugar sólo haya filamentos membranosos, o que haya mujeres que en el momento del parto presenten el himen intacto. Objeciones a las que responde aludiendo a casos concretos. Respecto a la primera, afirma que durante el periodo de la menstruación se produce una relajación de la membrana himen hasta el punto de poder permitir la penetración del miembro viril sin destruirse. En referencia a la segunda objeción considera que se trata de casos excepcionalmente raros, que salvo un caso que cita $\mathrm{Ca}$ -

$33 \operatorname{VIDAL}(1783)$, p. 52.

34 FODERE (1801), t. II, p. 22. 
puron de una recién nacida en la que no lo encontró, él nunca ha observado su ausencia. Del mismo modo que la afirmación más arriba reseñada de Heister, según el cual el himen desaparece poco a poco a medida que las niñas crecen, la considera completamente falsa, tal como él ha constatado en las observaciones que ha realizado al respecto. En lo referente a la tercera objeción, declara que el hecho de que haya mujeres que queden embarazadas manteniendo el himen, sólo prueba que la fecundación ha podido tener lugar sin que la virginidad haya sido destruida. Igualmente afirmará que si la membrana se mantiene intacta tras una violación, no es prueba de que esta no se haya producido, sino de que el acto de la copulación no se ha completado del todo ${ }^{35}$. En la misma línea argumenta Taylor, quien aporta casos de mujeres que han concebido conservando íntegro el himen ${ }^{36}$.

Hofmann defenderá también la idea de que es posible que una mujer haya realizado el coito con un hombre y que mantenga íntegra su virginidad física. Se puede dar la circunstancia de que el pene en estado de erección no haya entrado hasta la vagina y el estado de satisfacción se haya verificado en el vestíbulo, ya porque la resistencia del himen no ha permitido la introducción del pene, o bien porque la estrechez considerable de las partes genitales lo hayan impedido, completándose el coito en la vulva. Eso explicaría que en la mayoría de casos de violación en las niñas el himen se haya encontrado intacto ${ }^{37}$.

En resumen, se dan una serie de variables que pueden explicar tanto el coito como incluso la concepción sin que haya tenido lugar la destrucción del himen. Así, según Hofmann, se hace comprensible que durante tanto tiempo no se le haya concedido un valor absoluto al himen para comprobar la virginidad, aunque afirme que su rotura después del primer coito es lo más común, y que por lo tanto siempre será conveniente investigar sobre su estado cuando se trata de verificar que el coito ha tenido o no lugar.

Excepción en la tratadística de Medicina Legal es Orfila, quien, en una nota a pie de página, explica que ha decidido evitar tratar ex professo la cuestión de la virginidad con ánimo de no complicar más una cuestión que lo es ya de por sí bastante. Habla de lo dificultoso que sería determinar si una mujer continuaría siendo virgen si la introducción de un pene exiguo no rompiese el himen o, al contrario, si la introducción de un dedo o un objeto más volumi-

35 Devergie (1840), t. I, pp. 353-354.

36 TAYLOR, A.S. (1890), Tratado de Medicina Legal, 3 vols., traducido de la última edición inglesa y ajustado a la legislación española por Luís Marco, Madrid, Establecimiento tipográfico de Enrique Teodoro, t. II, pp. 728-729.

37 HOFMANN (1882), pp. 67-71. 
noso que el miembro viril lo rompiese ${ }^{38}$. Obviamente, aunque Orfila trata de eludir el tema, está realmente planteando otra cuestión de difícil solución si se mantiene la cuestión de la virginidad física, a saber: ¿la pérdida de la virginidad es debida exclusivamente a la destrucción del himen o se requiere que para que se considere dicha pérdida sea necesario el miembro viril como agente? Y si hay penetración y no hay destrucción del himen, ¿se puede hablar de pérdida de la virginidad, aun cuando permanezca intacto el himen? Estas dudas, planteadas por Orfila, apuntan a que la mera constatación de la existencia o ausencia del himen no son indicativas de la presencia o no de la virginidad, cuando la pérdida de ésta se entiende como la destrucción del himen por haber tenido acceso carnal con un hombre.

\section{Otros signos de la virginidad}

Dado que, como acabamos de ver, la sola presencia o ausencia del himen no es suficiente para afirmar con seguridad la desfloración, se ha recurrido tradicionalmente a la existencia de otros signos que de alguna manera indicasen si el estado de virginidad permanecía o no.

El interés por encontrar indicios de la virginidad de la mujer, incluso externos, se han dado en todos los tiempos y en las más diversas culturas. En la antigua Roma se medía el cuello de la joven antes de la noche de bodas con un hilo que se guardaba hasta el día después, entonces se le volvía a medir, y si le venía justo, no se dudaba de que la pérdida de la virginidad se había producido tiempo atrás, pero si el hilo venía corto, prueba de que el cuello había aumentado de volumen durante la noche, se proclamaba la virginidad de la joven. Otros indicios de la desfloración, que al igual que el de la dimensión del cuello son considerados en su mayoría como creencias supersticiosas ya en el siglo XVIII, son la alteración de la voz, la blandura de las alas de la nariz y de los pechos, del estado de los ojos, de olor de la orina, etc. ${ }^{39}$. Sin embargo, aunque se descarten algunos signos por considerarlos sin fundamento, se sigue manteniendo la creencia de que la conformación anatómica de la mujer que no ha cohabitado mantiene unas características peculiares. Así, para Fernández del Valle, en el cuerpo de la joven virgen se aprecia «la figura redonda del vientre, la de las mamas, el color de su pezón, que será

38 ORFILA (1847), t. I, p. 138.

39 Cfr. MonlaU, P.F. (1865), Higiene del matrimonio, Madrid, Imprenta y estereotipos de M. Ribadeneyra, pp. 119-120. 
algo amarillo» ${ }^{40}$. También para Foderé «quando una doncella está robusta, y es casta, tiene en todas las partes del cuerpo una elasticidad y frescura, que bastan por sí solas para distinguirla de la que ha perdido esta apreciable qualidad ${ }^{41}$. Los pechos ocuparán un lugar de atención preferente, dentro de la anatomía femenina, a la hora de determinar la virginidad de la mujer. Así, para Ferrer y Garcés, cuando estos, como los pezones, se presentan consistentes y están acompañados de otros signos en los genitales, se puede afirmar que no se ha producido el estupro ${ }^{42}$. Con el tiempo estas observaciones, aunque no se abandonen del todo, se matizarán. Casper afirma que la dureza y turgencia de los pechos son también indicadores de que una joven sana es virgen, no obstante reconoce que el estado de los pechos nada prueba por sí solo, pues es más bien la edad la que modifica ese estado ${ }^{43}$. A estas peculiaridades físicas, se les añade a veces un aspecto general que acompaña al estado de doncellez:

«Y si el semblante puro de una vírgen candorosa despierta en los que la miran el amor y el entusiasmo, es porque se ve en ella á una mujer con toda la inocencia, que se revela por la candidez de su rostro angelical» ${ }^{44}$.

Pero serán ciertas características de los órganos genitales femeninos donde la tratadística médico-forense de gran parte del siglo XIX crea haber encontrado signos propios de la virginidad. Por ejemplo, Orfila señala un conjunto de indicios para identificar la desfloración. Los grandes labios son gruesos, firmes y tersos, su cara interna es lisa y sonrosada, sus bordes libres se aproximan y tienden a cubrir la entrada de la vulva en la joven que es virgen, pero si la mujer es de cierta edad o ha padecido ciertas enfermedades como leucorrea, clorosis, etc., o si se ha entregado a la masturbación pueden desaparecer estos signos, igual que afirma que no es raro observarlo en las jóvenes que han cohabitado una sola vez. Los pequeños labios son pequeños, lisos, sonrosados, dotados de gran elasticidad, sensibles y compactos, pero basta la simple introducción en la vagina de un cuerpo más o menos voluminoso para que pierdan estos caracteres. El orificio de la vagina, es en general

40 Fernández del VAlle (1796), t. I, p. 306.

41 FODERÉ (1801), t. II, p. 35.

42 Vid. Ferrer y Garcés, R. (1848), Tratado de Medicina Legal, Barcelona, Imprenta y Librería de D. Pablo Riera, p. 192.

43 CASPER, J.L. (1884), Tratado práctico de Medicina Legal, 6 vols., traducido por Florencio Álvarez-Ossorio, Madrid, Establecimiento tipográfico de P. Núñez, t. I, p. 121.

44 FERRER Y GARCÉS (1848), p. 181. 
más estrecho antes que después de la desfloración; y el interior de esta presenta arrugas transversales próximas unas a otras, que disminuyen después de practicar la cópula ${ }^{45}$.

Algunas de estas características serán descartadas como indicadoras de la virginidad en los tratados que se publican a finales de siglo. Hofmann y, en el mismo sentido, Legrand du Saulle van a aportar razones que explican estas supuestas modificaciones anatómicas sin vinculación con el comercio sexual ${ }^{46}$.

\section{¿VÍCTIMAS O ESTAFADORAS?}

Al reconocimiento físico en la práctica forense se le añade un examen moral, que no es otra cosa que una indagación sobre hábitos, relaciones, reputación, etc., de las denunciantes de agresiones sexuales con el objetivo de desenmascarar las acusaciones espurias. Existe la creencia, muy generalizada en esta época, de que muchas de las denuncias que se presentan son fraudulentas: madres desnaturalizadas que fingen una agresión sexual sobre sus hijas con fines lucrativos, mujeres despechadas que declaran un falso estupro, mujeres que, cediendo a la relación sexual, luego alegan violación, etc. De ahí que la atención se redobla para desenmascarar los fraudes y, como consecuencia, la credibilidad de las víctimas de agresiones sexuales será muy cuestionada. Tal como explica Pedro Mata:

«Los tribunales de todos los paises se han ocupado en procesos de esta suerte. Jóvenes bastante astutas, que han sido engañadas por sus amantes ó que aspiran á la mano de ciertos hombres, no sienten empacho en hacer ostentación de su deshonra para que se compadezcan de ellas y sea aquella un cuerpo de delito, cuyo castigo la ponga en posesión de lo que ellas desean. Tal vez es una madre, un deudo que magulla y atropella á una muchacha ó á una niña, y la presenta luego ante el magistrado como prueba evidente de estupro, á fin de que el individuo ó individuos sobre quienes recaiga la acusacion, la indemnicen de esa pérdida de virginidad con

45 Orfila (1847), t. I, pp. 134-135. También encontramos estos signos en los tratados de PEIRÓ y RODRIGO y RODRIGO Y MARTíneZ (1832), p. 99; MATA (1846), t. I, pp. 107-112; FERrer y Garcés (1848), pp. 181-183; Rossell, A. (1848), Manual de Medicina Legal, Madrid, Establecimiento tipográfico de D. Ramón Rodríguez de Riera, pp. 122-123.

46 Hofmann (1882), pp. 62-63; Legrand du Saulle, H. (1886), Tratado de Medicina Legal de Jurisprudencia Médica y Toxicología, 4 vols., traducido al castellano por Teodoro Yáñez y Font, y adaptado a la legislación española por Carlos Núñez Granés, Madrid, El Cosmos Editorial, t. I, pp. 363-366. 
un puñado de oro, si ya no quiere alcanzar por este medio para la supuesta víctima la mano del acusado ${ }^{47}$.

La sospecha que recae sobre este tipo de denuncias no es consecuencia exclusiva de la naturaleza del delito, que por sus características suele consumarse sin la presencia de testigos, ni incluso por un beneficio potencial que pueda reportar, ya sea en forma de indemnización, u otro modo de desagravio. Es el hecho mismo de que sea mujer la demandante lo que induce a cuestionar la veracidad de la acusación.

«El médico forense debe estudiar profundamente y sagazmente el estado moral de la ofendida tanto como las señales de que hemos hecho mencion hasta aquí; y ha de ser muy difícil que no descubra una simulacion, por mucho que se preste el sexo débil al fingimiento, y el asunto de que se trata á la imputacion dirigida á quien pueda ser explotado mercantilmente ó en otro concepto» ${ }^{48}$.

Esta situación de descrédito del testimonio de la mujer nos lleva inevitablemente a pensar que sea una de las variables que contribuyan en este siglo a la escasa presencia de denuncias por violación de mujeres adultas, y menos aún si no ha concurrido la pérdida de la virginidad. Así, cuando Valentí i Vivó comenta unas estadísticas tomadas de la obra de Tardieu sobre la incidencia de la violación en el país vecino, en las que se aprecia en el periodo que va de 1851 hasta 1863 un aumento del número de agresiones a menores de edad, frente a un estancamiento respecto a las que tienen lugar sobre mujeres adultas, afirma:

«Pocas son en honor de la verdad en nuestro país los casos de desfloracion que nos obligan á intervenir como expertos, pero los que se presentan se ven por lo mismo rodeados de toda clase de dificultades y de muchos detalles escandalosos ${ }^{49}$.

El valor social que en esta época se le atribuye a la virginidad, la deshonra que para la mujer y para su familia suponen la pérdida de este estado serían también circunstancias que explicasen el escaso número de denuncias por violación.

Otro de los problemas a los que las mujeres víctimas de violación tenían que hacer frente cuando presentaban la correspondiente acusación era el de la

47 MATA (1844b), t. I, p. 61.

48 VAlentí I Vivó, I. (1873), Curso elemental de Medicina Legal, Barcelona, Imprenta de C. Verdaguer y Compañía, p. 292.

49 VAlentí I Vivó (1873), p. 297. 
creencia, muy generalizada, de que un hombre solo no podía violar a una mujer. Esta idea la encontramos en el tratado de Fernández del Valle:

«En la mayor parte de los Autores que tratan de los derechos á quienes pertenece, se lee estupro violento: esta violencia es aparente, porque es absolutamente imposible que se desflore á una doncella contra su voluntad, á menos que antes tóme algun medicamento Narcótico ó se le amenace con la muerte: atandola de pies y manos, podrá conseguirse; pero en los demás casos no se puede conceder semejante violencia» ${ }^{50}$.

La creencia de que esta forma de atentado no es posible, al menos si no es con la participación de varios hombres, será una constante en toda la tratadística decimonónica. Para ilustrarlo se suele recurrir a citas literarias. Entre las que más fortuna hicieron estaba la que refiere Voltaire sobre cierta reina que rechazó la acusación hecha por una mujer de que había sido violada. Para justificar la razón que le había llevado a ello, le dio una espada y le pidió que metiese su punta por una vaina que la reina tenía en la mano y en continuo movimiento. La mujer no consiguió envainar la espada ${ }^{51}$. Otro caso que refiere Mayart de Vouglans en su Tratado de los crímenes, citado por Mata ${ }^{52}$ es el de un tribunal que condenó a un joven acusado de violación a que diese a la mujer forzada una bolsa con dinero; a continuación lo autorizó para que se lo arrebatara, la mujer opuso tal resistencia que al joven le fue imposible recuperar la bolsa. El tribunal absolvió al joven fundándose en que si la mujer hubiese mostrado tanto empeño en defender su honestidad, al acusado le habría sido imposible forzarla.

No obstante, a lo largo del siglo se irán introduciendo otros matices como el de las fuerzas respectivas, entendiéndose que una mujer de constitución débil no puede ofrecer suficiente resistencia a un hombre corpulento, aunque sí una mujer robusta a un agresor de edad avanzada o de fuerza similar a la de ella. Asimismo, el que la mujer haya sido inmovilizada, esté en estado de inconsciencia, etc., hacen más viable el que se le dé crédito a su testimonio. Sin embargo, y tal como afirma Casper,

«es imposible sentar un principio general para decidir, si una mujer, en buen estado de salud, de unas fuerzas medianas, y sin haber perdido el conocimiento, puede ser violada por un solo hombre» ${ }^{53}$.

\footnotetext{
50 Fernandez del Valle (1796), t. I, p. 307.

51 Vid. ORFILA (1847), t. I, pp. 150-151.

52 MATA (1846), t. I, p. 99.

53 CASPER (1884), t. I, p. 145.
} 
Por lo que la incertidumbre y, consecuentemente, la sospecha sobre la denunciante estarán presentes para estos casos. De ahí que para disipar las dudas será necesario que la mujer pueda demostrar que se ha resistido a la violación.

Como acabamos de ver, la simple denuncia de la mujer no bastaba para que se considerase el hecho de la violación, eran imprescindibles signos que confirmaran la acusación, pero si la mujer no era virgen esos signos debían ser de lucha, contusiones, equimosis, etc. Era necesario que la mujer ofreciera resistencia aun cuando ello pudiera agravar la agresión, porque la ausencia de signos cuestionaba la veracidad de su testimonio.

Mas en el caso de que se presentasen dichos signos, aún se mantenía la sospecha de la probable anuencia de la mujer:

«Tambien pueden existir señales de violencia sin que la desfloración haya sido forzada; pocas mugeres hay que se entreguen sin resistencia á los deseos de un amante; las mas veces no parece que quieren ceder sino á la fuerza, aun en el caso que hubiesen preparado su desdicha; y ¿una muger no puede en estos combates amorosos haber esperimentado algunas contusiones, concluyendo por entregarse en los brazos de un hombre á quien fingía rechazar?» ${ }^{54}$.

Orfila presentará una argumentación similar. Plantea la cuestión del consentimiento o la fuerza en función de que la mujer sea virgen o no. En el primer caso, aduciendo que lo corriente es que el médico sea llamado para violaciones de niñas, basará su opinión en la desproporción de los órganos del hombre y la menor, o bien en que las dimensiones del miembro del hombre sean proporcionadas a las partes sexuales de la niña o incluso menores. Para la primera situación, junto a cardenales en brazos, pechos, mejillas, etc., lo frecuente es encontrar ciertos desordenes y destrozos en los órganos sexuales de la niña de mayor o menor consideración en función de la fuerza empleada y de la resistencia ofrecida por la víctima. En el caso de que el desfloramiento haya sido consentido se encontrarán las mismas señales en la joven, si se da esta desproporción del tamaño de los órganos sexuales y más aún si «cuando los individuos lejos de proceder con moderacion, son impetuosos é impacientes $\rangle^{55}$. Si ambas partes son proporcionadas, o incluso menores las del hombre, sólo considera que serán encontrados cardenales en función de la resistencia ofrecida. No obstante, también Orfila es de la opinión de que en determinadas circunstancias, aun cuando exista el consentimiento por parte de la mujer, esta

54 PeIRó y Rodrigo y Rodrigo y MARTínez (1832), p. 101.

55 ORFILA (1847), t. I, p. 151. 
pueda ofrecer al principio una cierta resistencia, como si formase parte de una especie de juego amoroso o de seducción que finalmente llegue a convertirse en una trampa para el amante:

«¿No podrá suceder que una joven decida [decidida] desde luego á resistir, empiece defendiéndose, se deje aun maltratar, y que despues bien pronto, lejos de oponer resistencia, cede gustosa á los deseos de su amante? No son raros los ejemplos de este género, y aun se han visto jóvenes tan perversas ó mal aconsejadas, que han acusado á sus amantes de haberlas violado, porque las han abandonado despues de gozarlas, y presentar como pruebas de violacion, los cardenales de las diversas partes del cuerpo, que solo son resultado de la primera resistencia» ${ }^{56}$.

Cuando el discurso se centra en la violación de una mujer que ya no es virgen, prostituta, o de aquellas que han tenido hijos, la mayoría de los autores confiesan la imposibilidad de encontrar signos que verifiquen el hecho. Por una parte, si la mujer se encuentra inconsciente, inmovilizada o bajo intimidación, de modo que no puede ofrecer resistencia, el diámetro que presenta el orificio de la vagina en estos casos, que permite el acceso carnal sin ocasionar la menor rubicundez o desgarro, así como la ausencia de himen, impiden un pronunciamiento acertado sobre si ha habido violación o no. Si por el contrario, la mujer está en condiciones de ofrecer resistencia, la violación se considera imposible, puesto que la mujer que ya ha cohabitado tiene la experiencia suficiente para impedir la penetración ${ }^{57}$. Orfila añade que otros signos como los cardenales han podido ser causados por la propia mujer, o bien haber sido causados con anterioridad a la fecha en que dice haber sido violada ${ }^{58}$.

Puesto que en la ley se recoge que la violación puede darse por fuerza o por intimidación, es obvio pensar que cuando se da bajo esta segunda circunstancia no se presenten signos de violencia. Como afirma Mata, «el abatimien-

56 Orfila (1847), t. I, pp. 151-152. También encontramos esta opinión en: DeVERGIE (1840), t. I, p. 371; Gómez PAmo, M. (1872), Manual completo de Medicina Legal y Toxicología, manual ordenado y traducido a partir de las obras de J. Briand, J. Bouis y J.L. Casper, por M. y J.R. Gómez Pamo, y adaptado a la legislación española por F. Romero Gilsanz, Madrid, Moya y Plaza, p. 134.

57 Estas argumentaciones se presentan de forma similar en: DEVERGIE (1840), pp. 358-9; BAYARD, H.-L. (1844), Elementos de Medicina Legal, traducido y adaptado a la legislación española por Manuel Sarrais y Bonafos, Madrid, Imprenta de la Viuda de Jordan e Hijos, p. 153; ORFILA (1847), pp. 152-153. Sin especificar estas razones, también se pronuncian en contra de la posibilidad de encontrar signos de violación en estos casos: PEIRÓ Y RODRIGO y RODRIGO Y MARTíNEZ (1832), p. 101; MATA (1857), t. I, p. 278; HOFMANN (1882), p. 62.

58 ORFILA (1847), t. II, p. 152 
to moral que produce el miedo ó el temor, postra á su vez las fuerzas físicas y no hay lucha, porque no hay resistencia» ${ }^{59}$. De modo que, según el médico catalán, cuando la violación ha tenido lugar por medio de la intimidación sobre una mujer que no es virgen «la ley podrá tener por evidente la cópula en su parte moral; pero se efectuará en lo físico, como si la forzada hubiese accedido á ello» ${ }^{60}$. Situación que no podemos calificar más que de lamentable para la mujer forzada que, no siendo virgen, decidía presentar la denuncia, en tanto que, si ofrecía resistencia ante la fuerza del agresor, los signos de la misma interpretados por el forense no eran indicadores necesariamente del empleo de la violencia, tal como afirma Orfila. Si, por el contrario, la violación se realizaba bajo intimidación y la mujer no presentaba resistencia física, entonces en el reconocimiento forense no se podía informar sobre violación.

Difícil, pues, se presentaba la situación para aquellas mujeres que denunciaban una agresión sexual; incluso los signos que más claramente podían apuntar a una causa violenta podían ser interpretados como motivados por un espíritu caprichoso y mudable, como el que se le atribuía a la mujer en esa época, que resistiendo al principio, luego cede voluntariamente. Sería necesario, pues, que la resistencia llegara hasta el grado del heroísmo, cuando se trataba de defender el honor, para que se disiparan las dudas sobre la veracidad de la denuncia.

«No es menos cierto que el pudor reacciona á veces hasta tal punto á la que valerosamente se defiende, que es imposible la satisfaccion en el agresor de sus lúbricos deseos, y de ahí ó el asesinato de la mujer ó el magullamiento de sus miembros, cara, cuello, mamas, hasta fracturas del femur, epilepsias, locuras y la muerte misma, como otras tantas consecuencias directas de la lucha empeñada» ${ }^{61}$.

Quizás debamos entender que el grado de resistencia que se le exigía a la mujer para dar crédito a su denuncia era proporcional al valor que durante el siglo XIX se le asignaba a la virginidad, por un lado, y a la honestidad entendida como continencia sexual, por otro, como la virtud moral más relevante atribuida a la mujer. Además, esta honestidad debía mostrarse de modo ostensible, lo que llevaba a que, para disipar posibles dudas, las denuncias debían ir acompañadas de signos evidentes de resistencia.

Pero la atención médica hacia los signos no se orientaba exclusivamente hacia la constatación de la anuencia de la mujer o su sincera resistencia al asalto sexual, sino que el interés forense se dirigía también hacia otros signos

59 MATA (1857), t. I, p. 279.

60 Mata (1857), t. I, p. 279.

61 VALENTí I VIVÓ (1873), p. 291. 
cuya presencia pudiesen revelar prácticas inmorales o transgresoras que delatasen una conducta incontinente en la mujer que presentase denuncia por estupro o violación. Signos que, en el caso de aparecer, podrían ser utilizados en contra de los intereses de la denunciante. Esto hace comprensible la aparición recurrente en la tratadística médica de consideraciones acerca de las huellas que delatan el abuso de los actos venéreos, signos que muestran tanto la práctica del onanismo como de una cierta frecuencia de la cohabitación con el hombre. De este modo, según Foderé:

«El uso freqüente de los placeres del amor, junto con el onanismo, á que suelen entregarse las mugeres lúbricas, muda la dulzura y flexibilidad de la voz, por una conseqüencia precisa de la absorcion del licor del varon, la cual produce en él este efecto; al mismo tiempo que la pérdida de la sustancia nerviosa en los actos carnales repetidos disminuye la elasticidad de los músculos, el tono del texido celular, y las fuerzas de todo el cuerpo» ${ }^{62}$.

Desde finales del siglo XVIII y durante el XIX el interés médico por la masturbación, tanto para señalar las consecuencias que el vicio solitario tiene para niños y adolescentes, como en su vertiente higienista para prevenir otros males, será considerable ${ }^{63}$. Se daba también la creencia de que los signos que quedan inscritos en el cuerpo de las onanistas son en muchos casos similares a los que manifiestan las menores que son víctimas de abusos. En este sentido Tardieu advierte que, a la hora de llevar a cabo el reconocimiento forense para los casos de violación, es necesario saber diferenciar los desórdenes que producen estos actos delictivos de los que son causados por la masturbación:

«No basta haber contrastado las lesiones inflamatorias ó la deformacion de las partes sexuales; hay que establecer además, que estos desórdenes no dimanan de otras causas, que de las violencias criminales; y entre estas causas, no las hay más á menudo invocadas, y, fuerza es decirlo, más legítimamente suspectas, que los hábitos de masturbacion» ${ }^{64}$.

62 FODERÉ (1801), t. II, pp. 35-36.

63 Cfr. SeOAne CegarRa, J.B. (2006), El placer y la norma. Genealogía de la educación sexual en la España contemporánea. Orígenes 1800-1920, Madrid, Octaedro; VÁZQUEZ GARCÍA, F. y SeOANe CegarRa, J.B. (2004), España y la cruzada médica contra la masturbación (1800-1900). Elementos para una genealogía, Hispania, 64 (3), n. ${ }^{\circ}$ 218, pp. 835-867; VÁzQUEZ García y MORENO MENGíbar (1997), pp. 94-130.

64 TARDIEU, A. (1882), Estudio médico-legal sobre los delitos contra la honestidad, traducido de la 7. ${ }^{\text {a }}$ edición francesa y anotado por Prudencio Sereñana y Partagás, Barcelona, La Popular, casa editorial de Francisco Pérez, pp. 109-110. 
La referencia a estos signos en los tratados forenses será frecuente a todo lo largo del siglo XIX, en ocasiones para diferenciarlos de los producidos por abusos, pero en otras, simplemente sin más justificación que la de mostrarlos como huellas de una conducta lúbrica en la mujer ${ }^{65}$, huellas que la descalifican en la defensa de este tipo de causas penales:

\begin{abstract}
«Cuando no existan estos signos característicos de hábitos de libertinaje, que excluirian toda presuncion de violacion, el médico fijará toda su atencion sobre los signos de violacion ó de desfloracion, signos que están, segun hemos dicho, subordinados al tiempo que ha transcurrido desde el atentado» ${ }^{66}$.
\end{abstract}

Pero no sólo estos signos contribuirán a acrecentar las sospechas sobre denuncias fraudulentas de las mujeres, también su conducta habitual, su reputación, será digna de consideración en el discurso médico, especialmente en la primera mitad de siglo ${ }^{67}$. Mata, por el contrario, se pronunciará en contra de que este tipo de cuestiones sean contempladas por el facultativo, pues debe ser el magistrado quien, en su opinión, deba calificarlas como oportunas o no ${ }^{68}$.

\title{
CONCLUSIONES
}

El análisis que el tratamiento de la violencia y la transgresión sexual ha tenido por parte de la Medicina Forense en la época considerada nos permite obtener una serie de conclusiones referidas a la tesis que tratamos de probar.

La labor de la Medicina Forense se encuentra en dependencia de lo que se halla legislado. En concreto, el campo de los llamados delitos contra la honestidad o delitos de incontinencia comprende una serie de conductas que van del rapto a la violación, pasando por el estupro o los abusos deshonestos. La tipificación como delitos del rapto y el estupro en el Código Penal de 1848 (y posteriormente en el de 1870) debe ser interpretada como una pervivencia de los valores específicos del Antiguo Régimen en materia sexual en las codi-

65 Como ejemplos de este tipo de consideraciones, además de los mencionados, véase Mata (1846), t. I, p. 108; Gómez PAMo (1872), p. 127; HofMANN (1882), p. 74; LegRAND DU SAULlE (1886), t. I, p. 364.

66 Gómez Pamo (1872), p. 128.

67 Vid. Belloc (1819), p. 38; PEIRÓ y Rodrigo y Rodrigo y MARTíneZ (1832), p. 101; DeVERGIE (1840), t. I, p. 374.

68 MATA (1857), t. I, p. 335. 
ficaciones decimonónicas ${ }^{69}$. Más concretamente, una pervivencia que refleja una continuidad en el modo en el que todavía en el siglo XIX se sigue entendiendo el papel que el sexo desempeña en el orden social. Esta circunstancia motivó que el interés forense principal respecto a la mujer fuese el de determinar si era virgen o no para los casos de denuncia de estupro, figura penal que se había construido a partir de la idea de la honestidad de la mujer, además, por supuesto, de para testificar acerca de si la violación se había consumado. Ciertamente, la propia reglamentación penal de la época exigía tales pruebas, de modo que podemos interpretar esta práctica, siguiendo a Foucault $^{70}$, como un elemento constitutivo de lo que este autor denomina dispositivo de alianza, es decir, un sistema de regulación de las relaciones de sexo basado en el matrimonio, en la fijación y desarrollo del parentesco y en la transmisión de bienes. Se trata de un dispositivo sustentado tanto en mecanismos coercitivos como en un sistema de creencias y saberes específicos. En este sentido, la virginidad aparece como la garantía de la transmisión de la herencia y el linaje, y el peritaje forense como una práctica orientada a su verificación.

La Medicina Forense decimonónica va a canalizar su labor profesional en el campo de los delitos contra la honestidad en dos direcciones fundamentalmente: por una parte, como ya hemos indicado, se orientará al esclarecimiento de las denuncias por estupro (las de rapto en última instancia se llevan al extremo de verificar si se ha dado aquél) y por otra, a establecer si se ha consumado la violación (que se sitúa en la cúspide de una gradación de la violencia que comprende los abusos deshonestos y la tentativa de violación).

Respecto al estupro se aprecia una evolución en el planteamiento médico, que va desde considerarlo a finales del siglo XVIII como principal tema de atención dentro de los delitos contra la honestidad a pronunciarse, como hace Mata a mediados de siglo XIX, por el abandono de las exploraciones médicas para constatar su posible comisión. Las razones que se aportan son de índole científica, en concreto, el cada vez mayor escepticismo sobre la posibilidad de

69 Si bien el estupro permanecerá durante mucho tiempo como figura penal en los códigos españoles, a partir de principios del siglo XX se empieza a cambiar el modo en que es contemplado. Primero en la doctrina jurídica, luego en la jurisprudencia y, finalmente, en la normativa. Básicamente el cambio se empezará a producir a partir de la consideración de la libertad sexual como bien jurídico protegido, en sustitución de la honestidad. Cfr. BoIX REIG, J. (1979), El delito de estupro fraudulento, Publicaciones del Instituto de Criminología de la Universidad Complutense de Madrid.

70 Foucault (1995), pp. 129-139. 
presentar pruebas objetivas respecto a la virginidad, motivo de su ausencia o momento en la que esta fue destruida. Pero también se puede interpretar este cambio de posición como un inicio en el distanciamiento de la labor médica del llamado dispositivo de alianza del que hablábamos más arriba ${ }^{71}$.

No afirmamos con ello que esto suponga un abandono por el interés de la virginidad, pues este se mantendrá durante todo el siglo. Aparte de razones de orden social o legal, también se da la circunstancia de que según el testimonio de los propios médicos la mayoría de los casos denunciados en esta época son los motivados por la violación de menores y mujeres jóvenes vírgenes. Por lo tanto, el interés por identificar los signos de la virginidad ocupará un lugar preferente en los tratados. Este interés no se limitará al estado de las partes más íntimas de la mujer, sino que se hará extensivo a otras manifestaciones físicas e incluso morales.

Todo ello contribuirá a conformar la imagen de la doncella, de la mujer casta, de la virtud, de la honestidad en suma, que no en vano constituye el bien jurídico protegido por la ley.

A esta mujer honesta se le opondrá, de forma más o menos explícita, el conjunto de mujeres que no son merecedoras de esta calificación: la mujer entregada al libertinaje, la de conducta moral dudosa, la onanista, la soltera que ha perdido la virginidad, sobre las que, como hemos visto, recaen en mayor medida las sospechas de denuncias espurias.

Esta distinción entre la mujer honesta y la que no lo es debemos entenderla dentro del contexto de la sociedad patriarcal decimonónica, y en función del papel que la honestidad de la mujer desempeña en aquella respecto al honor masculino. En el sentido de que el honor del hombre se encuentra, en parte, en dependencia de la honestidad de las mujeres con las que está emparentado. La normativa protege de forma tácita este vínculo, y la Medicina Legal aporta los fundamentos anatómicos al valor de la honestidad, convirtiendo la virginidad y sus signos en el eje central de sus observaciones y elaboraciones teóricas.

Como contrapartida, las mujeres de las que se sospecha que han perdido esta cualidad, y que por lo tanto quedan al margen del intercambio de capital simbólico sobre el que se fundamenta el dispositivo de alianza, son relegadas a un segundo plano del interés penal y médico, y consecuentemente se muestran más vulnerables respecto a las agresiones sexuales.

Esta vulnerabilidad se ve reflejada en tres órdenes diferentes: primero, el examen moral al que debe ser sometida la mujer. Se trata en suma de una

71 Ese mismo distanciamiento se operará más tardíamente en el ámbito jurídico tal como hemos apuntado en la nota 69. 
indagación sobre la reputación, que durante la primera mitad de siglo XIX será contemplada por parte de los forenses como un dato a tener en cuenta a la hora de elaborar sus informes para valorar la veracidad de la denuncia. En 1857 Mata va a proponer que estas cuestiones recaigan exclusivamente bajo la contemplación del magistrado, y no del facultativo. Obviamente, esta actitud aleja la labor médica del juicio moral de la víctima. Sin embargo, este distanciamiento no será absoluto. Mata, como el resto de autores, seguirá considerando que la aparición de signos de onanismo en el cuerpo de la mujer es un dato significativo, en tanto que se pueden confundir con los que producen los abusos, pero también en tanto que delatan en la mujer una cierta incontinencia sexual, lo que alimentaría la sospecha respecto a la resistencia o anuencia ante la agresión sexual. Hay, pues, un interés en las huellas que los actos venéreos dejan inscritos en el cuerpo de la mujer, huellas que serán el objeto de la mirada del médico y en las que este interpretará la comisión del acto delictivo, pero también las prácticas sexuales que no entren dentro del estricto orden moral sexual establecido en la época.

Al examen moral y a los signos del onanismo hay que sumar los prejuicios que durante el siglo XIX condicionaban la objetividad médica. Fundamentalmente los concernientes a que una mujer adulta no puede ser forzada por un hombre solo, y menos aún si esta no es virgen, ya que se le supone una experiencia suficiente para impedir la penetración; la sospecha de que una mujer en principio puede resistirse, como un modo de seducción, para luego acceder voluntariamente; y, por último, el hecho de que el propio sistema penal resarciese a las víctimas de violación o estupro, ya con compensaciones económicas o bien con la obligación del hombre de casarse con la mujer para el segundo caso, incrementaba la sospecha de denuncias espurias.

La aparición recurrente de estos prejuicios en los tratados que servirían como manuales para la formación de los facultativos no podía menos que condicionar una más que deseable objetividad para quienes tendrían que ejercer como peritos para los casos de violación. Sólo a mediados del siglo XIX los médicos empiezan a deslindar lo que son pruebas objetivas constatables por la observación forense de lo que son meras suposiciones, que deben quedar fuera de su campo y ser contempladas, junto con otros hechos circunstanciales, por los magistrados, aunque dichas cuestiones seguirán apareciendo más o menos matizadas en la mayoría de los tratados de la época.

Por lo tanto, el discurso médico forense decimonónico, en tanto que producido por hombres en el contexto de una sociedad patriarcal, refleja tanto la visión que se tiene acerca del papel que la mujer debe desempeñar en el ámbito sexual, con sus vínculos sociales y morales específicos, como la considera- 
ción del cuerpo femenino como depositario de determinados valores simbóli$\cos$ y que, consecuentemente, debe ajustarse a los límites que establece el orden moral sexual de la época.

Fecha de recepción: 20 de febrero de 2008

Fecha de aceptación: 17 de mayo de 2008 